\title{
Traveling-Wave Ion Mobility Mass Spectrometry Analysis of Isomeric Modified Peptides Arising from Chemical Cross-Linking
}

\author{
Luiz F. A. Santos, Amadeu H. Iglesias, Eduardo J. Pilau, \\ Alexandre F. Gomes, and Fabio C. Gozzo \\ Institute of Chemistry, University of Campinas and Instituto Nacional de Ciencia e Tecnologia de \\ Bioanalitica, Sao Paulo, Brazil
}

\begin{abstract}
Traveling-wave ion mobility (TWIM) coupled to mass spectrometry (MS) has emerged as a powerful tool for structural and conformational analysis of proteins and peptides, allowing the analysis of isomeric peptides (or proteins) with the same sequence but modified at different residues. This work demonstrates the use of the novel TWIM-MS technique to separate isomeric peptide ions derived from chemical cross-linking experiments, which enables the acquisition of distinct product ion spectra for each isomer, clearly indicating modification on different sites. Experiments were performed with four synthetic peptides, for which variable degrees of mobility separation were achieved. In cases of partially overlapping mobility arrival time distributions (ATDs), extracting the ATDs of fragment ions belonging to each individual isomer allowed their separation into two distinct ATDs. Accumulation over regions from the specific ATDs generates the product ion spectrum of each isomer, or a spectrum highly enriched in their fragments. The population of both modified peptide isomers was correlated with the intrinsic reactivities of different Lys residues from reactions conducted at different $\mathrm{pH}$ conditions. (J Am Soc Mass Spectrom 2010, 21, 2062-2069) (C) 2010 Published by Elsevier Inc. on behalf of American Society for Mass Spectrometry
\end{abstract}

\begin{abstract}
C hemical modification of proteins by $\mathrm{N}$ hydroxysuccinimide (NHS) esters is widely used in a series of experiments such as protein purification with biotin-avidin system [1, 2], fluorescence labeling [3-5], determination of amino acid sidechain solvent accessibility [6-8], and cross-linking [9, 10]. The use of NHS esters for cross-linking strategies has been applied for more than $30 \mathrm{y}$ to identify binding partners, [11] and a more recent approach relies on protein cross-linking coupled to mass spectrometry (MS) experiments to map three-dimensional structures of proteins (MS3D) $[12,13]$. Instruction manuals from commercial NHS-ester cross-linkers and most application literature state that NHS esters react exclusively with primary amines ( $N$-terminus and $\varepsilon$-amino group of Lys side chains), and that when reacted with sulfhydryl or hydroxyl groups, do not yield stable products $[14,15]$. However, recent studies showed that the side chains of other residues (such as Tyr and Ser) can also sometimes yield stable cross-link species when reacted with NHS esters [16-18]. Homobifunctional NHS esters are the most widely applied cross-linkers in MS3D experiments. Briefly, in the general workflow present in most MS3D analyses, proteins are subjected to cross-
\end{abstract}

Address reprint requests to Dr. F. C. Gozzo, Institute of Chemistry, University of Campinas, CP 6154, Campinas-SP, Brazil. E-mail: fabio@ iqm.unicamp.br linking with one of the many reagents available followed by enzymatic digestion and MS analysis $[9,10]$. After digestion, there are four types of products found in MS3D: unmodified peptides; intramolecular crosslinked peptides (Type 1), where the chemical reagent used links two residues in the same peptide; intermolecular cross-linked peptides (Type 2), where two peptides are connected by the cross-linker; and dead-end (Type 0), where one side of the cross-linker is linked to a peptide chain and the other side suffered hydrolysis [19]. As each one of these species gathers different structural features regarding protein structure [19], the correct detection and annotation of which residue is linked to the cross-linker is essential to obtain reliable data for protein structure elucidation [20-24]. Dead-end species can be used as structural probes as they may yield information about residue exposure or solvent accessibility [6, 7, 25, 26].

Ion mobility spectrometry (IMS), originally known as plasma chromatography, was introduced in the 1960s and consists of a gas-phase ion separation technique [27]. Species are separated based on their charge states and sizes/shapes, the latter being more rigorously described as their collision cross sections (CCS). Smaller ions collide less frequently with the buffer gas compared with larger ions, thus crossing the mobility cell faster. Traditionally, ions are injected into a drift cell (DC) filled with an inert gas (typically helium), in the 
presence of a weak electric field applied at the end of the cell, and are detected separately with respect to the time they take to traverse the cell. The first coupling of ion mobility to MS is credited to E. W. McDaniel who, between the 1950s and 1960s, developed drift cells coupled to a magnetic sector mass analyzer, with the objective of studying ion mobilities and ion-molecule reactions [28]. Instruments with quadrupole $[29,30]$ and time-of-flight [31-33] mass analyzers soon replaced those with magnetic sectors in such a way that, in the 1970s and 1980s, MS became the main technique for detection of mobility-separated ions, with the first commercial IMS-MS spectrometer being made available in 1971 [34]. Subsequent works by Jarrold et al. [35], Kemper and Bowers [36] yielded significant improvements for IMS-MS instruments, and thus the technique was applied for the analysis of carbon clusters [37, 38], amino acids [39], peptides and proteins [40, 41], nucleotides [42], and synthetic polymers [43]. Other types of ion mobility devices are the aspiration and differential types, for which instrumental details and applications have been described [44-49]. As an example of the technique's capability for isomer separation, Hill Jr. et al. [50] used nitrogen doped with $10 \%(S)-(+)$-butanol as a buffer gas in a DC instrument to resolve atenolol enantiomers by ion mobility.

Recently, traveling-wave ion mobility coupled to mass spectrometry (TWIM-MS) was introduced in commercial instruments. In this approach, ions are injected in a stacked-ring ion guide (SRIG) filled with a buffer gas [51], and are separated by a traveling voltage wave incorporated to the guide, in a process that has been previously detailed $[51,52]$. The range of application of the TWIM-MS technique has seen recent increase, as shown by studies of transition-metal complexes [53], proteins [54-56], and protein complexes [57-60].

In terms of gas-phase separation of isomeric ions by TWIM-MS, a study by Giles et al. [52] demonstrated the separation of isomeric peptides SDGRG and GRGDS, which present a CCS difference of only 5\%. Other TWIM separation studies were done with isomeric peptides containing the same number and type of amino acid residues but differing in sequence [61], phosphorylated peptides [62, 63], carbohydrates [64], isomeric alkyl anilines [65], flavonoids [66], and amino acids [67]. Thus, the TWIM-MS technique provides a facile method for analyzing modified peptides (or proteins) with same sequences but modifications at different residues, with the attraction of being available in commercial instruments.

The aim of this work was to employ the TWIM-MS technique, recently available in commercial instruments, to assist data analysis obtained in protein crosslinking experiments. More specifically, isomeric deadend species formed from peptides containing two possible cross-linker reactive sites were submitted to ion mobility separation. Reactions between peptides and the cross-linker were performed at three different $\mathrm{pH}$ conditions and the gas-phase behavior of the possible dead-end products for each peptide was investigated.

\section{Experimental}

\section{Materials}

$\mathrm{N}$-terminal acetylated peptides Ac-ARAKGAEFAVKAGVR (P1), Ac-RKRVWSEKGNMAR (P2), Ac-ARYTKDLSQRAFKGMR (P3), and free $N$-terminus peptide AGAKGAERLVKAGVR (P4) were obtained from Proteimax (Sao Paulo, SP, Brazil). Methanol (HPLC grade) was obtained from Tedia Chemicals (Cincinnati, OH, USA). Disuccinimidyl suberate (DSS) and all other reagents were obtained from Sigma-Aldrich (St. Louis, MO, USA) and used without further purification.

\section{Cross-Linking Reaction: Dead-End Species Formation}

Each peptide was solubilized in $50 \mathrm{mM}$ sodium phosphate buffer at three different $\mathrm{pH}$ conditions: 6.0, 7.0, and 8.0, to a final concentration of $40 \mu \mathrm{M}$. DSS was dissolved in dry $\mathrm{N}, \mathrm{N}$-dimethylformamide (DMF) (10 $\mathrm{mg} \mathrm{mL} \mathrm{m}^{-1}$ ) and added in 50:1 molar excess to each buffered peptide solution. Reactions were allowed to stand at room temperature for $45 \mathrm{~min}$, after which Tris. $\mathrm{HCl}$ buffer (1 M, pH 7.6) was added to a final concentration of $50 \mathrm{mM}$ to quench the cross-linking reaction.

\section{Mass Spectrometry and TWIM-MS Analysis}

Before analysis, all reaction products were desalted using Oasis HLB cartridges (Waters, Milford, MA, USA). The desalting procedure consisted of sample loading, followed by desalting with $1 \mathrm{~mL}$ of $\mathrm{H}_{2} \mathrm{O} / 0.1 \%$ formic acid and peptide elution with $1 \mathrm{~mL}$ of $\mathrm{MeOH} /$ $0.1 \%$ formic acid. Peptide samples were then diluted $1: 1$ with $\mathrm{H}_{2} \mathrm{O} / 0.1 \%$ formic acid and submitted to mass spectrometric analysis. All TWIM-MS measurements were carried out on a Waters Synapt HDMS (Waters Co., Manchester, UK) instrument, by direct infusion of samples at a $6 \mu \mathrm{L} \mathrm{min}^{-1}$ flow rate into the ESI source of the instrument, with capillary and cone voltages fixed at $3.0 \mathrm{kV}$ and $40 \mathrm{~V}$, respectively. A detailed description of the Synapt HDMS has been given elsewhere [52]; briefly, the instrument has a quadrupole/ion mobility/ orthogonal acceleration time-of-flight (Oa-TOF) geometry. The ion mobility stage contains three stacked-ring ion guides (SRIG), namely Trap, IMS, and Transfer. Ions transmitted through the quadrupole are accumulated at the Trap cell, periodically injected at the IMS cell and mobility separated, after which they are transferred to the Oa-TOF analyzer by the Transfer cell while maintaining mobility separation. TWIM-MS spectra are acquired by synchronizing the release of ions to the IMS cell with acquisition start at the Oa-TOF. Fragmentation 
can be performed in either the Trap or Transfer cells, allowing for a series of different experiments.

Ions corresponding to the +3 charge state from each modified peptide were chosen for TWIM-MS/MS experiments. Such precursor ions were selected at the resolving quadrupole, separated by TWIM, fragmented at the Transfer cell, and analyzed at the Oa-TOF. The Trap collision energy was fixed at $6 \mathrm{eV}$, while Transfer collision energy and ion mobility conditions such as gas pressure, wave height, and velocity were individually adjusted for each of the modified peptides and are described below. Argon was used as collision gas on the Trap and Transfer cells, while nitrogen $\left(\mathrm{N}_{2}\right)$ was used as IMS cell gas. All product ion spectra were processed using the deconvolution algorithm MaxEnt 3 (Waters Co.). The instrument was externally calibrated using phosphoric acid oligomers with $\mathrm{m} / \mathrm{z}$ ranging from 100 to 2000.

\section{Results and Discussion}

\section{TWIM Separation of Isomeric Dead-End Modified Peptides Formed at $\mathrm{pH} 7.0$}

Peptides Ac-ARAKGAEFAVKAGVR (P1), Ac-RKRVWSEKGNMAR (P2), Ac-ARYTKDLSQRAFKGMR (P3), and AGAKGAERLVKAGVR (P4) were used for the study. All peptides possess random sequences of 13 to 16 residues, two of which are necessarily Lys. All except for $\mathrm{P} 4$ are acetylated at the $\mathrm{N}$-terminus. The general experimental setup employed here for the analysis of isomeric dead-end species by TWIM-MS was similar to that used by Riba-Garcia et al. [68]. Reaction products containing a mixture of two or more dead-end species were directly infused in the instrument and the resolving quadrupole was set to select ions corresponding to triply charged states of those species, which were seen as either a single broad peak or two unresolved broad peaks in the arrival time distribution (ATD) display. Ion mobility conditions such as wave height, wave velocity, and IMS cell gas pressure were individually adjusted to optimize separation of isomers. The collision energy in the Transfer cell was then gradually increased until satisfactory precursor ion fragmentation was observed, and spectra were manually acquired at optimal collision energies. This experimental setup allows isobaric precursor ions to be partially separated in the IMS cell, while fragmentation at the Transfer cell maintains fragments time-aligned with their previously separated precursor ions.

To distinguish between different isomers, after acquisition with fragmentation in the Transfer cell, a product ion spectrum of the isomer mixture was obtained by combining over the full ATD. Then, individual ATDs were extracted from $y_{n} / y_{n}+156$ Da pairs of fragment ions of this spectrum, each belonging to one of the isomeric species, thus generating distinct extracted ATDs for each isomer. Sections from leading edge of the first ATD and the trailing edge of the second ATD were then accumulated separately. Using this approach, one can choose to accumulate ATD sections that show no or minimum overlap between the two individual ATDs, thus resulting in a pure or highly enriched product ion spectrum from each isomeric peptide. This approach was applied to peptides P1 to P4 using the optimized ion mobility conditions shown in Table 1 . As the individual ATDs have different apexes and shapes, the extracted region for each isomer was optimized for each peptide to accumulate the maximum area of one ATD while excluding or minimizing the overlap with the other ATD. Therefore, extraction regions may present different widths for each isomer.

To evaluate ATD profiles and product ion spectra obtained, an initial comparison was made for reactions performed with all four peptides at $\mathrm{pH}$ 7.0. The respective ATD obtained for P1 is displayed in Figure 1a. The observed distribution consists of two broad, unresolved peaks clearly showing the presence of at least two isomers of dead-end modified peptides. Regions 1 and 2 were accumulated separately, and corresponding product ion spectra are also displayed in Figure 1.

By extracting ATDs from $\mathrm{y}_{5}$ of $\mathrm{m} / \mathrm{z} 530.3$ and $\mathrm{y}_{5}{ }^{*}$ of $\mathrm{m} / \mathrm{z} 684.4$, the existence of two dead-end isomers becomes clear (Figure 1b). The observed y-ion series from the product ion spectrum of the ATD Region 1 for P1 (Figure 1c) is consistent with a dead-end modification on the second Lys residue (unmodified $\mathrm{y}_{4}$ and modified $\mathrm{y}_{5}{ }^{*}, \mathrm{y}_{6}{ }^{*}, \mathrm{y}_{7}{ }^{*}$, and $\mathrm{y}_{8}{ }^{*}$ ions). Conversely, the ATD Region 2 product ion spectrum (Figure 1d) displays unmodified $\mathrm{y}_{4}, \mathrm{y}_{5}, \mathrm{y}_{6}, \mathrm{y}_{7}$, and $\mathrm{y}_{8}$ ions, demonstrating the presence of the dead-end modification on the first Lys residue. No unmodified $\mathrm{y}_{5}, \mathrm{y}_{6}, \mathrm{y}_{7}$, or $\mathrm{y}_{8}$ ions were observed in the spectrum of ATD Region 1 (Figure 1c), neither were modified $\mathrm{y}_{5}{ }^{*}, \mathrm{y}_{6}{ }^{*}, \mathrm{y}_{7}{ }^{*}, \mathrm{y}_{8}{ }^{*}$ ions in the spectrum of ATD Region 2 (Figure 1d), indicating no contamination of the spectrum of one isomer with fragment ions of the other and vice versa. The ion containing the dead-end modification on the second Lys residue is more compact than the one modified on the first Lys residue, thus having a greater mobility and shorter drift time.

For P2 (Figure 2), the full ATD (Figure 2a) shows a single broad peak, with no apparent indication of two or more isomeric species. Extraction of ATDs from the modified $\mathrm{y}_{6}{ }^{*}$ ion of $\mathrm{m} / \mathrm{z} 832.4$ and unmodified $\mathrm{y}_{6}$ ion of $\mathrm{m} / \mathrm{z} 676.3$ yields individual ATDs with more overlap

Table 1. Optimized instrumental conditions used for TWIMMS analyses of P1-P4 triply charged dead-end ions

\begin{tabular}{|c|c|c|c|c|}
\hline \multirow[b]{2}{*}{ Peptide } & \multicolumn{2}{|c|}{ IMS } & \multirow{2}{*}{$\begin{array}{l}\text { Transfer } \\
\text { CE (eV) }\end{array}$} & \multirow{2}{*}{$\begin{array}{c}\text { IMS Gas } \\
\text { Pressure (mbar) }\end{array}$} \\
\hline & $\mathrm{WV}\left(\mathrm{m} \mathrm{s}^{-1}\right)$ & WH (V) & & \\
\hline P1 & 550 & 7.5 & 42 & 0.54 \\
\hline P2 & 550 & 7.5 & 42 & 0.54 \\
\hline P3 & 450 & 11 & 54-57 & 0.93 \\
\hline P4 & 800 & 11 & $32-35$ & 0.54 \\
\hline
\end{tabular}

$\mathrm{WV}=$ wave velocity; $\mathrm{WH}=$ wave height $\mathrm{CE}=$ collision energy. 


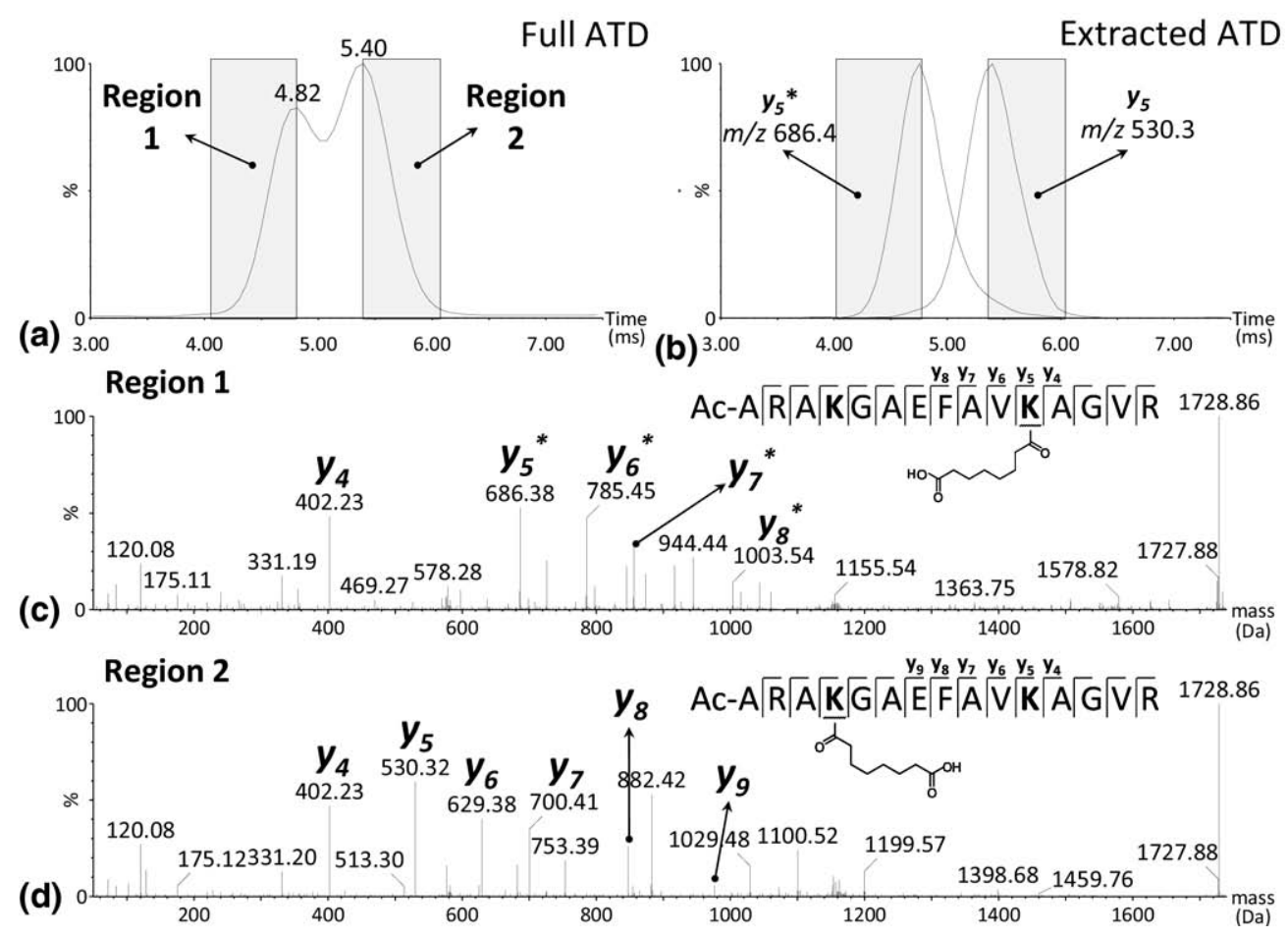

Figure 1. Arrival time distributions and product ion spectra for P1 dead-end isomers. (a) Full ATD obtained for P1. (b) Extracted ATDs from unmodified $(\mathrm{m} / \mathrm{z} 530)$ and modified $(\mathrm{m} / \mathrm{z} 684)$ y 5 product ions of P1 isomers. Product ion spectra corresponding to (c) leading (Region 1) and (d) trailing (Region 2) edges of the first and second extracted ATDs, respectively. Ions marked with an asterisk $\left(^{*}\right)$ are modified with a DSS dead-end (+156 Da mass shift).

than observed for P1 (Figure 2b). Combining over ATD Regions 1 and 2 separately results in different spectra, compatible with two isomeric structures containing the dead-end modification on different Lys residues, which may be present but are not as separated as observed for P1.

For P2, the ATD Region 1 product ion spectrum (Figure 2c) displays unmodified $\mathrm{y}_{5}$ and modified $\mathrm{y}_{6}{ }^{*}$, $\mathrm{y}_{7}{ }^{*}$, and $\mathrm{y}_{8}{ }^{*}$, whereas the ATD Region 2 product ion spectrum (Figure 2d) displays unmodified $\mathrm{y}_{5}, \mathrm{y}_{6}, \mathrm{y}_{7}$, and $\mathrm{y}_{8}$ ions. As no complete mobility separation was achieved for $\mathrm{P} 2$, one extracted product ion spectrum contains minor, low intensity fragment ions from the other isomer and vice versa, but these fragments have intensities below $10 \%$. This shows that Regions 1 and 2 (Figure $2 \mathrm{~b}$ ) correspond to the highly enriched product ion spectra of dead-end modifications on the second and first Lys residues, respectively (Figure $2 \mathrm{c}$ and $\mathrm{d}$ ).

The same behavior of $\mathrm{P} 2$ is observed for $\mathrm{P} 3$ (data not shown), for which there are unmodified $\mathrm{y}_{3}$ and modified $\mathrm{y}_{4}{ }^{*}, \mathrm{y}_{5}{ }^{*}$, and $\mathrm{y}_{6}{ }^{*}$ in ATD Region 1 , as well as unmodified $\mathrm{y}_{3}, \mathrm{y}_{4}, \mathrm{y}_{5}$, and $\mathrm{y}_{6}$ ions in ATD Region 2. No complete mobility separation was achieved for P3 as well, so that ATD Region 1 corresponds to a highly enriched product ion spectrum of dead-end modification on the second Lys residue, and ATD Region 2, on the first Lys residue.

These data show that even if an isomeric mixture appears as a single broad peak in the full ATD, by extracting the ion current from its leading and trailing edges it is possible to verify the presence of two distinct product ion spectra, confirming the existence of two different species that overlap in the mobility separation. The smaller degree of separation observed for dead-end isomers of P2 and P3 may be thought of as smaller CCS differences than those of P1 isomers, resulting in a greater overlap of individual ATDs. If the fragmentation pattern of the studied precursor ion is known, as is the case for all studied peptides, one can also plot extracted ATDs from pairs of modified and unmodified fragments, which produce unique ATDs for each isomer and allow measuring their distinct drift times.

The last peptide studied, $\mathrm{P} 4$, contains three reactive sites, namely the $\mathrm{N}$-terminus and the two Lys residues also present in other peptides, so that up to three distinct dead-end isomers could be produced from the cross-linking reaction. Figure 3a contains the full ATD obtained by analysis of the more complex $\mathrm{P} 4$ reaction mixture, displaying a single peak that is broader than that observed for P2 and P3, possibly due to the presence of three dead-end isomers.

The product ion spectrum obtained by combining over ATD Region 1 (Figure 3b) displays an unmodified $\mathrm{y}_{4}$ ion, in addition to modified $\mathrm{y}_{5}{ }^{*}, \mathrm{y}_{6}{ }^{*}, \mathrm{y}_{7}{ }^{*}$, and $\mathrm{y}_{8}{ }^{*}$ ions (Figure 3c), indicating that this region corresponds to the dead-end modification on the second Lys residue. The spectrum obtained by combining over ATD Region 2 (Figure $3 b$ ) shows unmodified $\mathrm{y}_{4}, \mathrm{y}_{5}, \mathrm{y}_{6}, \mathrm{y}_{7}$, and $\mathrm{y}_{8}$ 
(a)
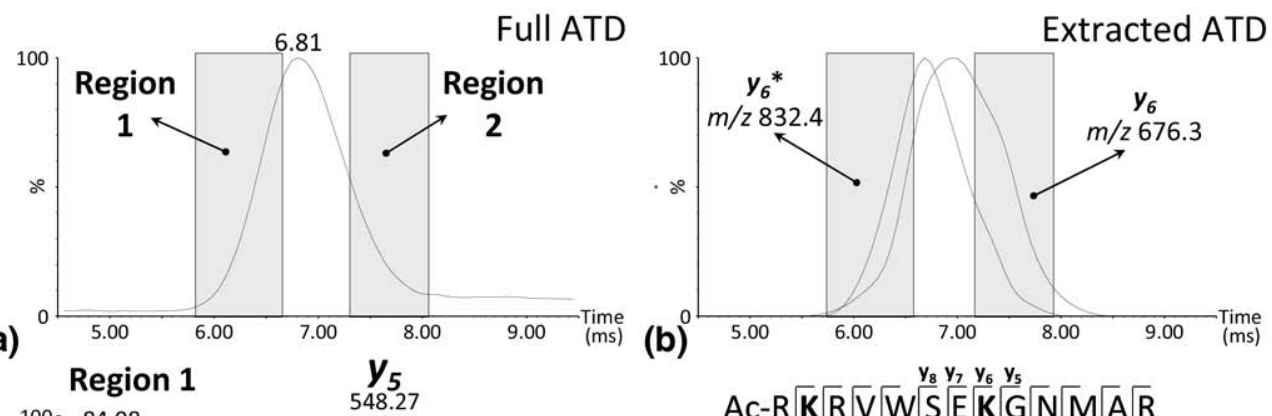

(c)

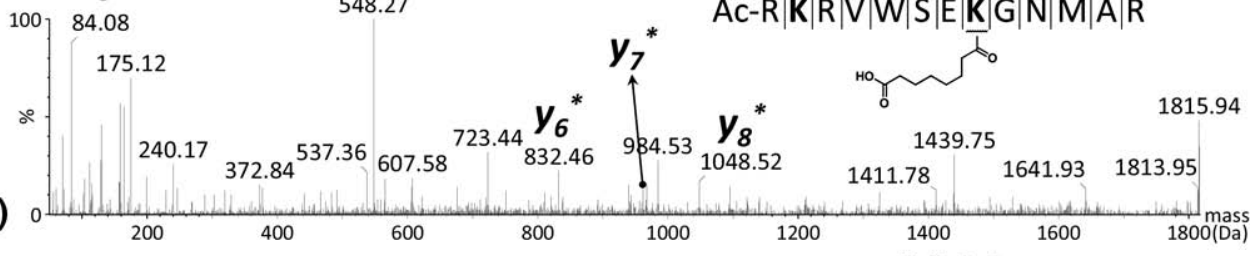

(b)

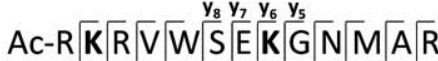

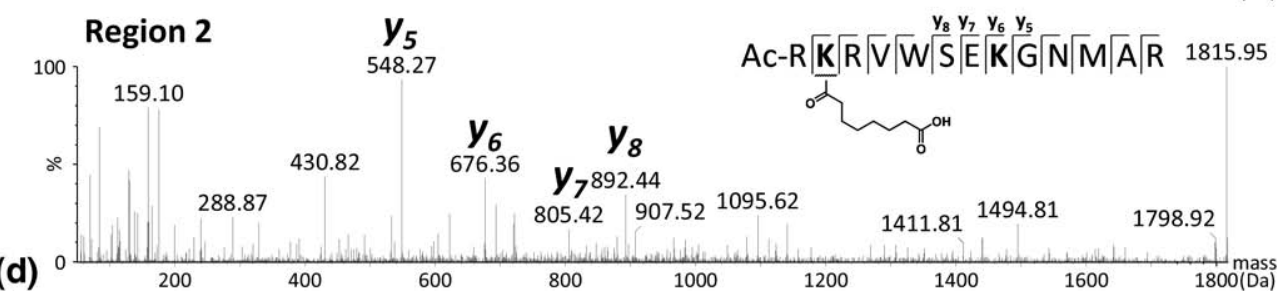

Figure 2. Arrival time distributions and product ion spectra for P2 dead-end isomers. (a) Full ATD obtained for P2. (b) Extracted ATDs from unmodified $(\mathrm{m} / \mathrm{z} 676)$ and modified $(\mathrm{m} / \mathrm{z} 832) \mathrm{y}_{6}$ product ions of P2 isomers. Product ion spectra corresponding to (c) leading (Region 1) and (d) trailing (Region 2) edges of the first and second extracted ATDs, respectively. Ions marked with an asterisk $\left(^{*}\right)$ are modified with a DSS dead-end (+156 Da mass shift).

ions (Figure 3d), which demonstrates that the dead-end modification is either at the $N$-terminus or first Lys residue. Inspection of the low $\mathrm{m} / \mathrm{z}$ region of the spectrum of Figure $3 d$ reveals unmodified $b_{2}$ and $b_{3}$ ions, as well as modified $b_{1}{ }^{*}$ and $b_{2}{ }^{*}$ ions, indicating that ATD Region 2 represents dead-end modifications that occurred either at the $\mathrm{N}$-terminus or first Lys residue. One can infer from the observed distributions that gas-phase conformations of dead-end modifications for peptide P4 on the $\mathrm{N}$-terminus and first Lys residue have very similar CCS values, which results in them being grouped in ATD Region 2 with no separation, whereas the gas-phase conformation for modification on the second Lys residue yields a CCS that is slightly different than that of the other two, resulting in separation into ATD Region 1.

\section{Effect of Reaction $\mathrm{pH}$ on the Reactivity of Lysines}

As mobility analysis can reveal the modified Lys residue, cross-linking reactions performed at different $\mathrm{pH}$ conditions were analyzed by TWIM-MS to retrieve differences in reactivity of Lys residues due to different chemical environments. The cross-linking reactions were performed for the four peptides at $\mathrm{pH} 7.0,6.0$, and 8.0 , and the triply charged ions from dead-end species were isolated in the quadrupole, followed by TWIM-MS analysis. As a representative example, mobility data from isomeric dead-end modified P2 products gener- ated in this manner are shown in Figure 4. In this figure, full extracted ATDs from the unmodified $\mathrm{y}_{6}$ and modified $\mathrm{y}_{6}{ }^{*}$ fragment ions from $\mathrm{P} 2$ in each $\mathrm{pH}$ condition are compared.

Comparison of the arrival time distributions (Figure 4) shows a decrease in the population of ions containing the dead-end modification on the second Lys residue ( $\mathrm{y}_{6}{ }^{*}$ ions of $\mathrm{m} / \mathrm{z}$ 832.4) as the $\mathrm{pH}$ increases, represented by the dashed-line ATDs. From this observation, one can infer that for P2, a higher $\mathrm{pH}$ condition favors modification on the first Lys residue (unmodified $\mathrm{y}_{6}$ ions of $m / z$ 676.3), slightly increasing its proportion with respect to modification on the second Lys residue, which presents a higher reactivity at lower $\mathrm{pH}$. Differences in reactivity of individual Lys residues have also been observed in a study performed by Guo et al. [69], in which bovine cytochrome $c$ was subjected to chemical cross-linking after partial acetylation of its Lys residues. It was shown that the pKa of Lys residues in the protein varies over two units, which can be correlated to differences in their chemical environment, steric hindrance effects, and solvent accessibility. There is also some evidence regarding the assistance of neighboring residues in the reaction of Ser, Thr, and Tyr residues towards NHS esters, such as the works by Mädler et al. [70] In this study, the His residue was shown to be capable of increasing the reactivity of hydroxyl-containing amino acid residues towards NHS esters to levels comparable to or even greater than Lys, 


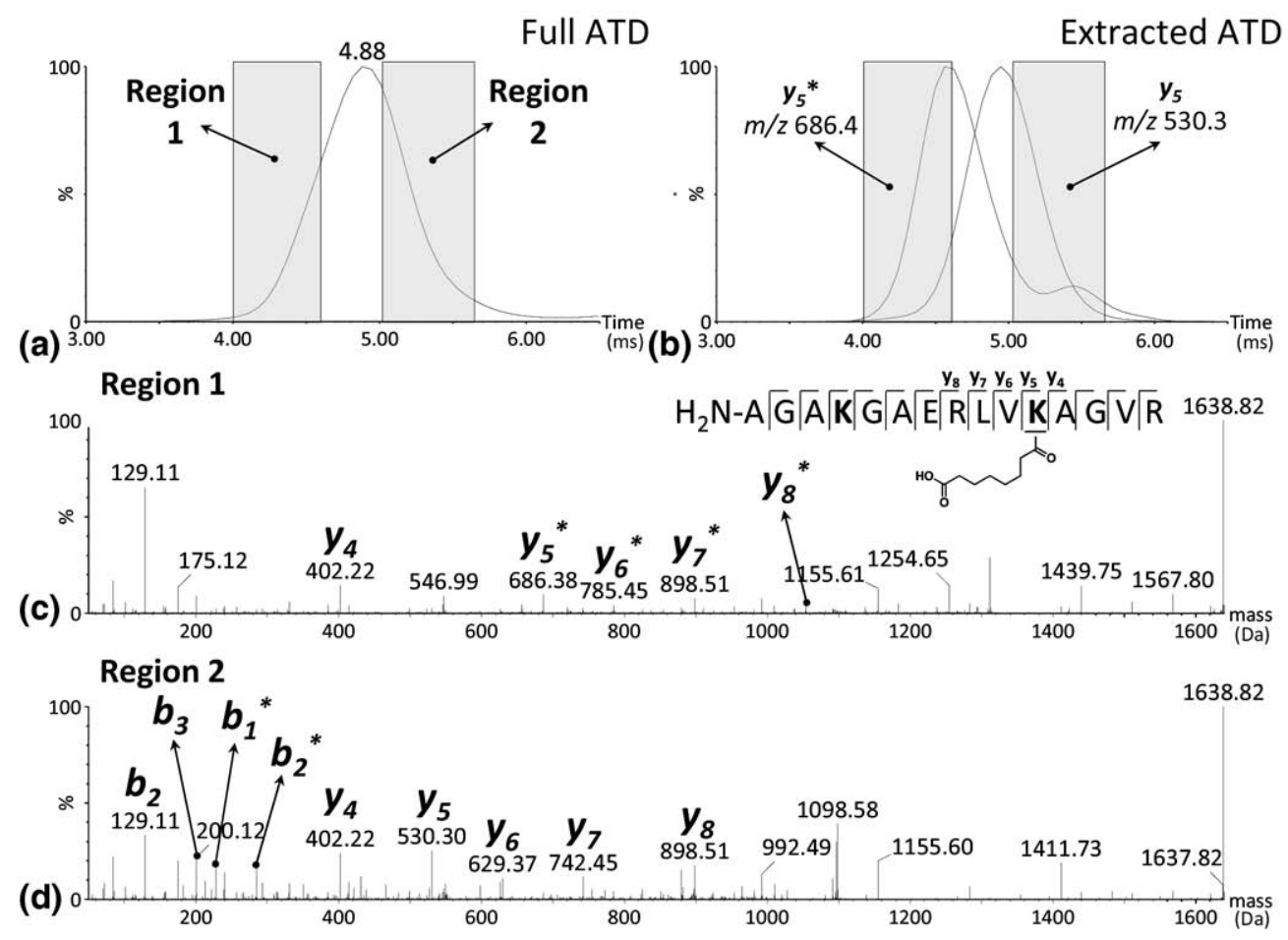

Figure 3. Arrival time distributions and product ion spectra for P4 dead-end isomers. (a) Full ATD obtained for P4. (b) Extracted ATDs from unmodified $(\mathrm{m} / \mathrm{z} 686)$ and modified $(\mathrm{m} / \mathrm{z} 530) \mathrm{y}_{5}$ product ions of P4 isomers. Product ion spectra corresponding to (c) leading (Region 1) and (d) trailing (Region 2) edges of the first and second extracted ATDs, respectively. Ions marked with an asterisk $\left(^{*}\right)$ are modified with a DSS dead-end (+156 Da mass shift).

depending on the $\mathrm{pH}$ values. All these factors that have been reported as affecting the reactivity of Lys residues are dependant on the extent to which the respective chemical groups are protonated or deprotonated and thus available to interact, which in turn is affected by the $\mathrm{pH}$ of the reaction medium.

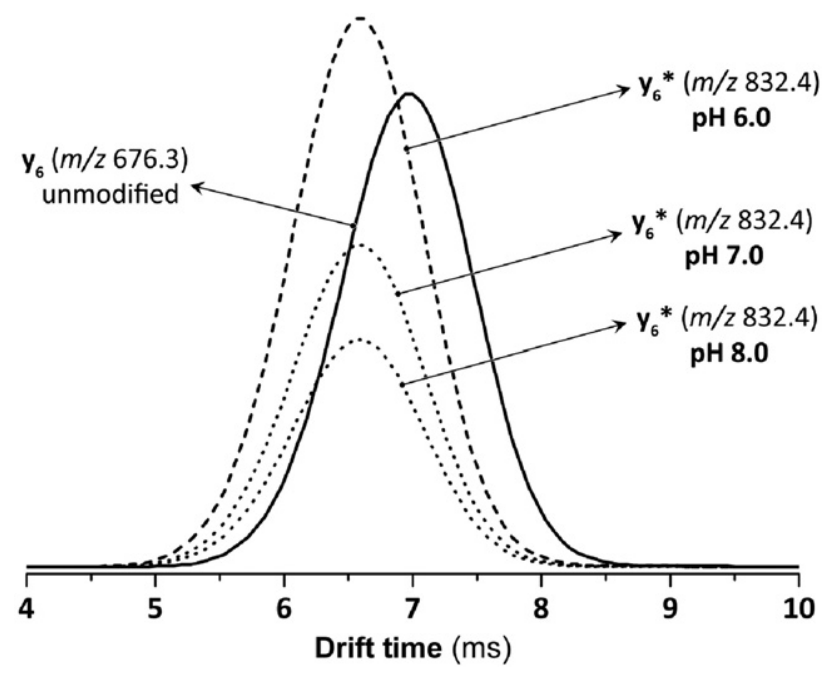

Figure 4. Extracted arrival time distributions from unmodified $\mathrm{y}_{6}$ (solid line) and DSS dead-end modified $\mathrm{y}_{6}{ }^{*}$ (dashed lines) product ions of $\mathrm{P} 2$ from reactions with DSS at $\mathrm{pH}$ 6.0, 7.0, and 8.0. Relative intensities have been normalized to the unmodified $\mathrm{y}_{6}$ ion.
This neighboring effect is observed for $\mathrm{P} 2$, for which the higher $\mathrm{pH}$ favors the deprotonation of the Glu residue next to the second Lys which, in turn, favors the deprotonation of the neighboring Lys, making it more reactive towards the NHS ester. On the other hand, the first Lys is surrounded by two Arg residues, which will be protonated at the range of $\mathrm{pH}$ conditions used, thus being unable to deprotonate the first Lys.

The same analysis was performed for the remaining peptides (data not shown). For P1 it was observed that the proportion of the isomer with dead-end modification on the second Lys residue sharply decreases from $\mathrm{pH} 6.0$ to 8.0, relative to modification on the first Lys residue, whereas for $\mathrm{P} 3$, modification on the second Lys residue seems to be favored at $\mathrm{pH} 6.0$ and 8.0 , and at $\mathrm{pH}$ 7.0, the opposite is observed. Interestingly for P4, ATD Region 2, which corresponds to modification on the $\mathrm{N}$-terminus or first Lys residue, is always greatly favored over modification on the second Lys residue because of the presence of two possible reaction sites in ATD Region 2. In view of the diverse range of observed relative proportions of dead-end modifications on the first and second Lys residues, one can infer that the effect of $\mathrm{pH}$ variation on the formation of each isomer is quite complex and dependant on the peptide sequence, which in turn dictates the conformation of the molecule in aqueous solution, protonated or deprotonated states of its amino acid side chains, and types of 
chemical groups neighboring the Lys residue in solution conformations.

\section{Conclusion}

In summary, the present work demonstrated the application of traveling-wave ion mobility mass spectrometry to resolve isomeric ions from dead-end modified peptides formed in typical cross-linking experiments. Although separation at the baseline level could not be obtained, knowledge of the fragmentation pattern of studied precursor ions can be used to generate individual ATDs for each dead-end isomer. This was achieved by extracting the ATDs from pairs of $y_{n} / y_{n}+156$ Da fragment ions from the product ion spectrum obtained by combining over the full ATD of the unresolved mixture, thus providing an easy method for visualization of individual drift times. This type of approach is straightforward and can be extended to other modifications that are present in single amino acid residues, as each isomer may be identified by its complementary band y-ion sequences on product ion spectra. The extracted ATD chromatograms can be used quantitatively to study intrinsic reactivities of individual residues, as shown for cross-linkers and Lys residues.

\section{Acknowledgments}

The authors acknowledge support for this work by the Sao Paulo Proteomics Network (FAPESP 2004/14,846-0 and FINEP 01.07.0290.00), Instituto Nacional de Ciencia e Tecnologia de Bioanalitica (FAPESP 08/57,805-2 and CNPq 573672/2008-3), $\mathrm{CNPq}$ and CAPES.

\section{References}

1. Gruis, D. B.; Price, E. M. The Nucleotide Binding Folds of the Cystic Fibrosis Transmembrane Conductance Regulator are Extracellularly Accessible. Biochemistry 1997, 36, 7739-7745.

2. Patchornik, G. Purification of His-Tagged Proteins with [Desthiobiotin\#BSA\#EDTA] Conjugates Exhibiting Resistance to EDTA. Bioconj. Chem. 2008, 19, 673-679.

3. Shell, S. M.; Hess, S.; Kvaratskhelia, M.; Zou, Y. Mass Spectrometric Identification of Lysines Involved in the Interaction of Human Replication Protein A with Single-Stranded DNA. Biochemistry 2005, 44, 971978.

4. Ioffe, M. V.; Gorbenko, G. P.; Kinnunen, P. K. J.; Tatarets, A. L.; Kolosova, O. S.; Patsenker, L. D.; Terpetsching, E. A. Tracing LysozimeLipid Interactions with Long-Wavelength Saquarine Dyes. J. Fluoresc. 2007, 17, 65-72.

5. Fan, J.; Pope, L. E.; Vitols, K. S.; Huennekens, F. M. Affinity Labeling of Folate Transport Proteins with the N-Hydroxysuccinimide Ester of $\gamma$-Isomer of Fluorescein-Methotrexate. Biochemistry 1991, 30, 4573-4580.

6. Gabant, G.; Augier, J.; Armengaud, J. Assessment of Solvent Residues Accessibility Using Three Sulfo-NHS-Biotin Reagents in Parallel: Application to Footprint Changes of a Methyltransferase Upon Binding Its Substrate. J. Mass Spectrom. 2008, 43, 360-370.

7. Shkriabai, N.; Datta, S. A. K.; Zhao, Z.; Hess, S.; Rein, A.; Kvaratskhelia, M. Interactions of HIV-1 Gag with Assembly Cofactors. Biochemistry 2006, 45, 4077-4083.

8. Barnhill, H. N.; Reuther, R.; Ferguson, P. L.; Dreher, T.; Wang, Q. Turnip Yellow Mosaic Virus as a Chemoaddressable Bionanoparticle. Bioconj. Chem. 2007, 18, 852-859.

9. Back, J. W.; Jong, L.; Muijsers, A. O.; Koster, C. G. Chemical CrossLinking and Mass Spectrometry for Protein Structural Modeling. J. Mol. Biol. 2003, 331, 303-313.

10. Sinz, A. Chemical Cross-Linking and Mass Spectrometry to Map Three-Dimensional Protein Structures and Protein-Protein Interactions. Mass Spectrom. Rev. 2005, 25, 663-682.

11. Lomant, A. J.; Fairbanks, G. Chemical Probes of Extended Biological Structures: Synthesis and Properties of the Cleavable Protein Cross- linking Reagent $\left[{ }^{35} \mathrm{~S}\right]$ Dithiobis(succinimidyl propionate). J. Mol. Biol. 1976, 104, 243-261.

12. Chen, Z. A.; Jawhari, A.; Fischer, L.; Buchen, C.; Tahir, S.; Kamenski, T.; Rasmussen, M.; Lariviere, L.; Bukowski-Wills, J.-C.; Nilges, M.; Cramer, P.; Rappsilber, J. Architecture of the RNA Polymerase II-TFIIF Complex Revealed By Cross-Linking and Mass Spectrometry. EMBO J. 2010, 29, 717-726.

13. Tubb, M. R.; Silva, R. A. G. D.; Fang, J.; Tso, P.; Davidson, W. S. A Three-Dimensional Homology Model of Lipid-free Apolipoprotein A-IV Using Cross-Linking and Mass Spectrometry. J. Biol. Chem. 2008, 283, 17314-17323.

14. Hermanson, G. T. Bioconjugate Techniques, 2nd ed.; Academic Press, Elsevier Inc.: San Diego, 2008, p. 171.

15. Guo, X.; Bandyopadhyay, P.; Schilling, B.; Young, M. M.; Fujii, N.; Aynechi, T.; Guy, R. K.; Kuntz, I. D.; Gibson, B. W. Partial Acetylation of Lysine Residues Improves Intraprotein Cross-linking. Anal. Chem. 2008, 80, 951-960.

16. Madler, S.; Bich, C.; Touboul, D.; Zenobi, R. Chemical Cross-Linking with NHS Esters: A Systematic Study on Amino Acid Reactivities. J. Mass Spectrom. 2009, 44, 694-706.

17. Swaim, C. L.; Smith, J. B.; Smith, D. L. Unexpected Products from the Reaction of the Synthetic Cross-Linker 3,3-Dithiobis(Sulfosuccinimidyl propionate), DTSSP with Peptides. J. Am. Soc. Mass Spectrom. 2004, 15, 736-749.

18. Leavell, M. D.; Novak, P.; Behrens, C. R.; Schoeniger, J. R.; Kruppa, G. H. Strategy for Selective Chemical Cross-linking of Tyrosine and Lysine Residues. J. Am. Soc. Mass Spectrom. 2004, 15, 1604-1611.

19. Schilling, B.; Row, R. H.; Gibson, B. W.; Guo, X.; Young, M. M. MS2Assign, Automated Assignment and Nomenclature of Tandem Mass Spectra of Chemically Cross-Linked Peptides. J. Am. Soc. Mass Spectrom. 2003, 14, 834-850.

20. Lee, Y. J. Mass Spectrometric Analysis of Cross-Linking Sites for the Structure of Proteins and Protein Complexes. Mol. BioSyst. 2008, 4, $816-823$.

21. Huang, B. X.; Kim. H. Y.; Dass, C. Probing Three-Dimensional Structure of Bovine Serum Albumin by Chemical Cross-Linking and Mass Spectrometry. J. Am. Soc. Mass Spectrom. 2004, 15, 1237-1247.

22. Kalkhof, S.; Sinz, A. Chances and Pitfalls of Chemical Cross-Linking with Amine-Reactive N-hydroxysuccinimide Esters. Anal. Bioanal. Chem. 2008, 392, 305-312.

23. Pimenova, T.; Nazabal, A.; Roschitzki, B.; Seebacher, J.; Rinner, O.; Zenobi, R. Epitope Mapping on Bovine Prion Protein Using Chemical Cross-Linking and Mass Spectrometry. J. Mass Spectrom. 2008, 43, 185-195.

24. Iglesias, A. H.; Santos, L. F. A.; Gozzo, F. C. Collision-Induced Dissociation of Lys-Lys Intramolecular Cross-Linked Peptides. J. Am. Soc. Mass Spectrom. 2009, 4, 557-566.

25. Iglesias, A. H.; Santos, L. F. A.; Gozzo, F. C. Identification of CrossLinked Peptides by High-Resolution Precursor Ion Scan. Anal. Chem. 2010, 82, 909-916.

26. King, G. J.; Jones, A.; Kobe, B.; Huber, T.; Mouradov, D.; Hume, D. A.; Ross, I. L. Identification of Disulfide-Containing Chemical Cross-Links in Proteins Using MALDI-TOF/TOF-Mass Spectrometry. Anal. Chem. 2008, 80, 5036-5043.

27. Kanu, A. B.; Dwivedi, P.; Tam, M.; Matz, L.; Hill, H. H. Jr. Ion Mobility-Mass Spectrometry. J. Mass Spectrom. 2008, 43, 1-22.

28. McDaniel, E. W.; Martin, D. W.; Barnes, W. S. Drift-Tube Mass Spectrometer for Studies of Low-Energy Ion-Molecule reactions. Rev. Sci. Instrum. 1962, 33, 2-7.

29. Albritton, D. L.; Miller, T. M.; Martin, D. W.; McDaniel, E. W. Mobilities of Mass-Identified Ions in Hydrogen. Phys. Rev. 1968, 171, 94-102.

30. McDaniel, E. W. Possible Sources of Large Error in Determinations of Ion-Molecule Reaction Rates with Drift Tube-Mass Spectrometers. J. Chem. Phys. 1970, 52, 3931-3935.

31. McAfee, K. B. Jr.; Sipler, D. P.; Edelson, D. Mobilities and Reactions of Ions in Argon. Phys. Rev. 1967, 160, 130-135.

32. Edelson, D.; Morrison, J. A.; McKnight, L. G.; Sipler, D. P. Interpretation of Ion-Mobility Experiments in Reacting Systems. Phys. Rev. 1967, 164, $71-75$.

33. Young, C .E.; Edelson, D.; Falconer, W. E. Water Cluster Ions: Rates of Formation and Decomposition of Hydrates of the Hydronium Ion. J. Chem. Phys. 1970, 53, 4295-4302.

34. Karasek, F. W.; Cohen, M. J.; Carroll, D. I. Trace Studies of Alcohols in the Plasma Chromatography-Mass Spectrometer. J. Chromatogr. Sci. 1971, 9, 390-392.

35. Kuk, Y.; Jarrold, M. F.; Silverman, P. J.; Bower, J. E.; Brown, W. L. Preparation and Observation of Si10 clusters on a Au(001)- $(5 \times 20)$ Surface. Phys. Rev. B 1989, 39, 11168-11170.

36. Kemper, P. R.; Bowers, M. T. A Hybrid Double-Focusing Mass Spectrometer-High-Pressure Drift Reaction Cell to Study Thermal Energy Reactions of Mass-Selected Ions. J. Am. Soc. Mass Spectrom. 1990, 1, 197-207.

37. Bowers, M. T.; Kemper, P. R.; von Helden, G.; Van Koppen, P. A. M. Gas-Phase Ion Chromatography: Transition Metal State Selection and Carbon Cluster Formation. Science 1993, 260, 1446-1451.

38. Gotts, N. G.; von Helden, G.; Bowers, M. T. Carbon Cluster Anions: Structure and Growth from C5- to C62-. Int. I. Mass Spectrom. Ion Processes 1995, 149, 217-229.

39. Wyttenbach, T.; Witt, M.; Bowers, M. T. On the Stability of Amino Acid Zwitterions in the Gas Phase: The Influence of Derivatization, Proton 
Affinity, and Alkali Ion Addition. J. Am. Chem. Soc. 2000, 122, 3458-3464.

40. Srebalus, C. A.; Li, J.; Marshall, W. S.; Clemmer, D. E. Gas-Phase Separations of Electrosprayed Peptide Libraries. Anal. Chem. 1999, 71, 3918-3927.

41. Thalassinos, K.; Slade, S. E.; Jennings, K. R.; Scrivens, J. H.; Giles, K.; Wildgoose, J.; Hoyes, J.; Bateman, R. H.; Bowers, M. T. Ion Mobility Mass Spectrometry of Proteins in a Modified Commercial Mass Spectrometer. Int. J. Mass Spectrom. 2004, 236, 55-63.

42. Gidden, J.; Baker, E. S.; Ferzoco, A.; Bowers, M. T. Structural Motifs of DNA Complexes in the Gas Phase. Int. J. Mass Spectrom. 2005, 240, 183-193.

43. Gidden, J.; Wyttenbach, T.; Jackson, A. T.; Scrivens, J. H.; Bowers, M. T. Gas-Phase Conformations of Synthetic Polymers: Poly(Ethylene Glycol), Poly(Propylene Glycol), and Poly(Tetramethylene glycol). J. Am. Chem. Soc. 2000, 122, 4692-4699.

44. Kanu, A. B.; Dwivedi, P.; Tam, M.; Matz, L.; Hill, H. H. Ion MobilityMass Spectrometry. J. Mass Spectrom. 2008, 43, 1-22.

45. Purves, R. W.; Guevremont, R.; Day, S.; Pipich, C. H.; Matyjaszczyk, M. S. Mass Spectrometric Characterization of a High-Field Asymmetric Waveform Ion Mobility Spectrometer. Rev. Sci. Instrum. 1998, 69, 4094-4105.

46. Guevremont, R.; Purves, R. W. Atmospheric Pressure Ion Focusing in a High-Field Asymmetric Waveform Ion Mobility Spectrometer. Rev. Sci. Instrum. 1999, 70, 1370-1383.

47. Guevremont, R. High-Field Asymmetric Waveform Ion Mobility Spectrometry: A New Tool for Mass Spectrometry. J. Chromatogr. A 2004, 1058, 3-19.

48. Sacristan, E.; Solis, A. A. A Swept-Field Aspiration Condenser as an Ion-Mobility Spectrometer. IEEE Trans. Instrum. Measurement 1998, 47, 769-775.

49. Solis, A. A.; Sacristan, E. Designing the Measurement Cell of a SweptField Differential Aspiration Condenser. Revista Mexicana de Fisica 2006, 52, 322-328.

50. Dwivedi, P.; Wu, C.; Matz, L. M.; Clowers, B. H.; Siems, W. F.; Hill, H. H. Jr. Gas-Phase Chiral Separations by Ion Mobility Spectrometry. Anal. Chem. 2006, 78, 8200-8206.

51. Giles, K.; Pringle, S. D.; Worthington, K. R.; Little, D.; Wildgoose, J. L.; Bateman, R.H.Applications of a Traveling Wave-Based Radio-FrequencyOnly Stacked Ring Ion Guide. Rapid Commun. Mass Spectrom. 2004, 18, 2401-2414.

52. Pringle, S. D.; Giles, K.; Wildgoose, J. L.; Williams, J. P.; Slade, S. E.; Thalassinos, K.; Bateman, R. H.; Bowers, M. T.; Scrivens, J. H. An Investigation of the Mobility Separation of Some Peptide and Protein Ions Using a New Hybrid Quadrupole/Traveling Wave IMS/oa-TOF instrument. Int. J. Mass Spectrom. 2007, 261, 1-12.

53. Williams, J. P.; Bugarcic, T.; Habtemariam, A.; Giles, K.; Campuzano, I.; Rodger, P. M.; Sadler, P. J. Isomer Separation and Gas-Phase Configurations of Organoruthenium Anticancer Complexes: Ion Mobility Mass Spectrometry and Modeling. J. Am. Soc. Mass Spectrom. 2009, 6, 11191122.

54. Hilton, G. R.; Thalassinos, K.; Grabenauer, M.; Sanghera, N.; Slade, S. E.; Wyttenbach, T.; Robinson, P. J.; Pinheiro, T. J. T.; Bowers, M. T.; Scrivens, J. H. Structural Analysis of Prion Proteins by Means of Drift Cell and Traveling Wave Ion Mobility Mass Spectrometry. J. Am. Soc. Mass Spectrom. 2010, 21, 845-854.
55. Scarff, C.; Patel, V. J.; Thalassinos, K.; Scrivens, J. H. Probing Hemoglobin Structure by Means of Traveling-Wave Ion Mobility Mass Spectrometry. J. Am. Soc. Mass Spectrom. 2009, 20, 625-631.

56. Smith, D. P.; Giles, K.; Bateman, R. H.; Radford, S. E.; Ashcroft, A. E. Monitoring Co-Populated Conformational States During Protein Folding Events Using Electrospray Ionization-Ion Mobility SpectrometryMass Spectrometry. J. Am. Soc. Mass Spectrom. 2007, 18, 2180-2190.

57. Van Duijn, E.; Barendregt, A.; Synowsky, S.; Versluis, C.; Heck, A. J. R. Chaperonin Complexes Monitored by Ion Mobility Mass Spectrometry. J. Am. Chem. Soc. 2009, 131, 1452-1459.

58. Pukala, T. L.; Ruotolo, B. T.; Zhou, M.; Politis, A.; Stefanescu, A.; Leary, J. A.; Robinson, C. V. Subunit Architecture of Multiprotein Assemblies Determined Using Restraints from Gas-Phase Measurements. Structure 2009, 17, 1235-1243.

59. Hyung, S.-J.; Robinson, C. V.; Ruotolo, B. T. Gas-Phase Unfolding and Disassembly Reveals Stability Differences in Ligand-Bound Multiprotein Complexes. Chem. Biol. 2009, 16, 382-390.

60. Ruotolo, B. T.; Benesch, J. L. P.; Sandercock, A. M.; Hyung, S.-J.; Robinson, C. V. Ion Mobility-Mass Spectrometry Analysis of Large Protein Complexes. Nature Prot. 2008, 3, 1139-1152.

61. Hill, H. H.; Hill, C. H.; Asbury, G. R.; Wu, C.; Matz, L. M.; Ichiye, T. Charge Location on Gas-Phase Peptides. Int. J. Mass Spectrom. 2002, 219, 23-37.

62. Ruotolo, B. T.; Gillig, K. J.; Woods, A. S.; Egan, T. F.; Ugarov, M. V.; Schultz, J.; A.; Russel, D. H. Analysis of Phosphorylated Peptides by Ion Mobility-Mass Spectrometry. Anal. Chem. 2004, 76, 6727-6733.

63. Thalassinos, K.; Grabenauer, M.; Slade, S. E.; Hilton, G. R.; Bowers, M. T.; Scrivens, J. H.; Characterization of Phosphorylated Peptides Using Traveling Wave-Based and Drift Cell Ion Mobility Mass Spectrometry. Anal. Chem. 2009, 81, 248-254.

64. Zaia, J.; Campuzano, I.; Giles, K.; Bateman, R.; Keith, C.; Costello, C. E. Electrospray Ion Mobility Spectrometry of Isomeric Carbohydrates. Glycobiology 2006, 11, 1140-1140.

65. Benassi, M.; Corilo, Y. E.; Uria, D.; Augusti, R.; Eberlin, M. N. Recognition and Resolution of Isomeric Alkyl Anilines by Mass Spectrometry. J. Am. Soc. Mass Spectrom. 2009, 20, 269-277.

66. Campuzano, I.; Giles, K. SYNAPT G2 High Definition Mass Spectrometry: Ion Mobility Separation and Structural Elucidation of Natural Product Structural Isomers (2009). Retrieved August 13, 2010 from the website: http://www.waters.com/webassets/cms/library/docs/ 720003041en.pdf.

67. Campuzano, I.; Giles, K.; Neeson, K.; Richardson, K. SYNAPT G2 High Definition Mass Spectrometry: Separation and Collision Cross-Section Determination of Leucine and Isoleucine by Traveling Wave Ion Mobility Mass Spectrometry (2009). Retrieved August 13, 2010 from the website: http://www.waters.com/webassets/cms/library/docs/ 720003028en.pdf.

68. Riba-Garcia, I.; Giles, K.; Bateman, R. H.; Gaskell, S. J. Evidence for Structural Variants of a- and b-Type Peptide Fragment Ions Using Combined Ion Mobility/Mass Spectrometry. J. Am. Soc. Mass Spectrom. 2008, 19, 608-613.

69. Guo, X.; Bandyopadhyay, P.; Schilling, B.; Young, M. M.; Fujii, N.; Aynechi, T.; Guy, R. K.; Kuntz, I. D.; Gibson, B. W. Partial Acetylation of Lysine Residues Improves Intraprotein Cross-Linking. Anal. Chem. 2008, 80, 951-960.

70. Mädler, S.; Bich, C.; Touboul, D.; Zenobi, R. Chemical Cross-Linking with NHS Esters: A Systematic Study on Amino Acid Reactivities. J. Mass Spectrom. 2009, 44, 694-706. 